\title{
Neoadjuvant treatments in triple-negative breast cancer patients: where we are now and where we are going
}

This article was published in the following Dove Press journal: Cancer Management and Research

\section{Claudia Omarini \\ Giorgia Guaitoli \\ Stefania Pipitone \\ Luca Moscetti \\ Laura Cortesi \\ Stefano Cascinu \\ Federico Piacentini \\ Department of Medical and Surgical Sciences for Children \& Adults, Division of Medical Oncology, University Hospital of Modena, Modena, Italy}

\begin{abstract}
Triple-negative breast cancer (TNBC) remains the poorest-prognosis breast cancer (BC) subtype. Gene expression profiling has identified at least six different triple-negative subtypes with different biology and sensitivity to therapies. The heterogeneous nature of TN tumors may justify the difficulty in treating this BC subtype. Several targeted agents have been investigated in clinical trials without demonstrating a clear survival benefit. Therefore, systemic chemotherapy remains the cornerstone of current clinical practice. Improving the knowledge of tumor biology is mandatory for patient management. In stages II and III, neoadjuvant systemic treatment is an effective option of care. The achievement of a pathological complete response represents an optimal surrogate for survival outcome as well as a test for tumor drug sensitivity. In this review, we provide a brief description of the main predictive biomarkers for tumor response to systemic treatment. Moreover, we review the treatment strategies investigated for TNBCs in neoadjuvant settings focusing on experimental drugs such as immunotherapy and poly [ADP-ribose] polymerase inhibitors that hold promise in the treatment of this aggressive disease. Therefore, the management of TNBC represents an urgent, current, unmet need in daily clinical practice. A key recommendation is to design biology-driven clinical trials wherein TNBC patients may be treated on the basis of tumor molecular profile.
\end{abstract}

Keywords: triple-negative breast cancer, neoadjuvant chemotherapy, BRCA, platinum, immunotherapy, PARP-1 inhibitors

\section{Introduction}

Currently, the treatment of patients with triple-negative breast cancer (TNBC) is the biggest challenge in the breast cancer (BC) scenario. TNBCs are defined by the absence of both hormone (estrogen and progesterone) receptors and HER2 overexpression. ${ }^{1}$ TNBCs represent a heterogeneous group of BCs with different treatment sensitivity and prognosis. Preclinical studies have identified at least six different molecular subtypes: two basal-like (BL1 and BL2), an immunomodulatory (IM), a mesenchymal (M), a mesenchymal stem-like (MSL), and a luminal androgen receptor (LAR). ${ }^{2}$

In the early stages, the use of neoadjuvant systemic treatment (NST) is the standard of care in TNBCs. Patients who achieve a pathological complete response (pCR) with primary therapy have improved survival outcomes. ${ }^{3,4}$ Standard neoadjuvant regimens include anthracyclines, taxanes, and cyclophosphamide. ${ }^{5,6}$ Platinum-based chemotherapy has been proposed but is not yet recommended by available guidelines. Different systemic treatment options have been investigated besides the use of chemotherapy. ${ }^{7-12}$ However, there are no approved targeted therapies for TNBC in the neoadjuvant setting,
Department of Medical and Surgical Sciences for Children \& Adults, Division of Medical Oncology, University Hospital of Modena, Via del Pozzo 7I, 4III22 Modena, Italy

Tel +3959422 2845

Email claudia.omarini@gmail.com 
although many different drugs have been studied and still others are currently being tested.

Clearly, there is a major need to better understand the characteristics and the clinical behavior of TNBCs with an aim to develop effective treatments for this BC subtype. The identification of molecular targets is essential for the design of clinical trials that investigate new treatment strategies. In this article, we review the literature on the use of NST in TNBCs. We focus on the molecular markers able to predict response/resistance to therapies. Moreover, we review the recent data on experimental drugs tested, and discuss findings concerning immunologic checkpoint inhibitors in this population. The main, ongoing clinical trials conducted in this field are reported as well.

\section{Predictive factors of response/resistance to neoadjuvant treatment}

The known, investigated, predictive factors of response/resistance to NST in patients with TNBC are shown in Figure 1 and listed further.

\section{Breast-related cancer antigen I}

TNBCs are likely to be breast-related cancer antigen 1 (BRCA1) mutation carriers or to have gene expression profiles similar to BRCA1-deficient tumors. ${ }^{13}$ BRCA genes play an important role in DNA double-strand break repair, contributing to the maintenance of DNA stability. ${ }^{14}$ Approximately $20 \%$ of all TNBCs show loss or inactivation of BRCA genes, resulting in an inefficient repair mechanism. ${ }^{15,16}$ Besides a mutation in $B R C A 1 / B R C A 2$, hypermethylation of both - the BRCA1 promoter and Fanconi anemia gene $(F A N C F)$ - result in a BRCA-like phenotype (also called the "BRCAness" tumors). The BRCA status is considered a predictive factor of response to chemotherapy and poly [ADPribose] polymerase (PARP) inhibitory agents. With regard to chemotherapy, tumor cell lines lacking functional $B R C A 1$ or 2 have increased sensitivity to DNA cross-linking agents such as platinum and to DNA-damaging chemotherapy agents such as anthracycline (Table 1). ${ }^{17}$ In two clinical studies conducted in TNBC patients treated with neoadjuvant single-agent cisplatin, pCR rates in $B R C A$-mutated women were $100 \%$ and $83 \%$, respectively. ${ }^{15,18}$ Moreover, a significant difference in pCR rates has been found between $B R C A 1$-mutated and $B R C A 1$-wild-type women treated with anthracycline and taxane regimens $(57.1 \%$ vs $29 \% ; p<0.001) .{ }^{16}$ On the other hand, preclinical evidence has shown a negative correlation between the BRCA1 mutation and taxane sensitivity due to the loss of a pro-apoptotic pathway activated in response to taxane-induced DNA damage. ${ }^{19}$ Furthermore, the increased sensitivity to DNA double-strand break agents has been confirmed in BRCA-like tumors that have a homologous recombination deficiency (HRD) similar to BRCA-mutated

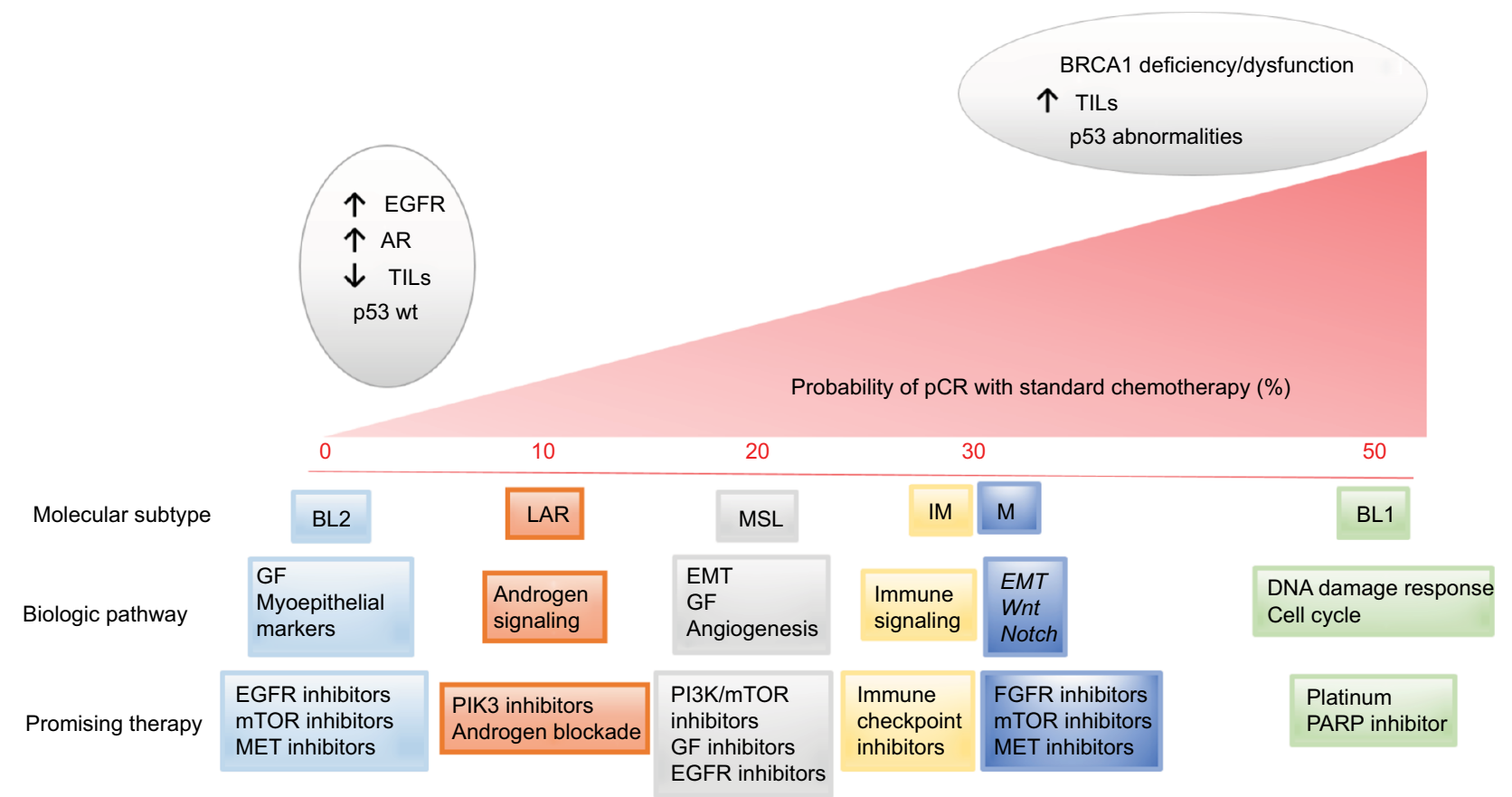

Figure I Triple negative breast cancer (TNBC) molecular subtypes classified according to gene expression and the main involved pathways. Each of these subclasses show varying pathological complete response $(P C R)$ rates following standard neoadjuvant chemotherapy. Promising therapies for every molecular subtype have been suggested. 
Table I pCR rate reported in published clinical trials in TNBC BRCA-mutated (BRCA mt) patients

\begin{tabular}{|c|c|c|c|c|c|c|}
\hline Study & Study design & $\begin{array}{l}\text { TNBC } \\
n\end{array}$ & $\begin{array}{l}\text { BRCA mt } \\
\mathrm{n}\end{array}$ & Treatment & PCR definition & $\begin{array}{l}\text { PCR BRCA } \\
\mathrm{mt} \%\end{array}$ \\
\hline Byrsky et al ${ }^{15}$ & Phase II & 107 & 82 & Cisplatin & ypT0/is ypNo & 61 \\
\hline Wang et $\mathrm{al}^{16}$ & Retrospective & 956 & 68 & Anthracycline $+/-$ taxane/taxane & ypTO/is ypNO & 53.8 \\
\hline Silver et a $\left.\right|^{18}$ & Phase II & 28 & 2 & Cisplatin & ypTO/is ypNo & 100 \\
\hline Telli et $\mathrm{a}^{20}$ & Pooled analysis & 93 & 19 & Carboplatin + gemcitabine + iniparib & ypTO/is ypNO & 47 \\
\hline
\end{tabular}

Abbreviations: TNBC, triple negative breast cancer; pCR, pathological complete response.

ones. A pooled analysis of six phase II trials conducted in TNBC patients treated with platinum demonstrated that patients with a high HRD score had an increased pCR rate compared to HR-non-deficient patients (53\% vs $18 \%$ ) regardless of the $B R C A$ mutation status. ${ }^{20}$

\section{Molecular subtypes}

Lehmann et al analyzed gene expression profiles in 587 TNBCs and identified six different subtypes: BL1, BL2, IM, M, MSL, and LAR. ${ }^{21} \mathrm{BL}$ tumors are characterized by a high frequency of chromosomal rearrangements, genomic instability, and $B R C A 1$ or $B R C A 2$ mutations. In particular, BL1 tumors are usually enriched in cell-cycle and DNA-damage-response genes that justify their high sensitivity to DNA-damaging agents such as platinum. In contrast, BL2 cancers frequently overexpress growth factor receptors, such as epidermal growth factor receptor (EGFR), IGF1R, and myoepithelial markers with low probability of tumor response to chemotherapy. ${ }^{21}$ More recent data, presented at the San Antonio Breast Cancer Symposium (SABCS) 2016, confirmed how BL1 tumors were likely to achieve a higher pCR rate compared to other TNBC subtypes ( $38 \%$ vs $20 \%, p=0.015$ ). ${ }^{22}$ Both M and MSL are enriched in pathways associated with EMT (epithelial-mesenchymal transition) and cell motility. This $\mathrm{BC}$ subtype frequently presents PI3KCA-activating mutations. According to genomic expression, mesenchymal tumor cells have displayed responses to dasatinib (abl/src inhibitor) and a PI3K/mTOR inhibitor. The LAR subtype cells express androgen receptors with sensitivity to an AR antagonist such as bicalutamide. Finally, IM tumors are enriched in genes involved in immune cell processes and may be considered the more promising subtypes for immunotherapies. ${ }^{21}$ This molecular classification seems to have not only a predictive value but also a prognostic one. A significant difference in relapse-free survival (RFS) has been found among molecular subtypes. In particular, LAR tumors show a decreased RFS compared with the BL1, IM, and MSL subtypes (HR $=2.9,3.2$, and 10.5, respectively; $p<0.05)$. There were no reported significant differences in terms of distant-metastasis-free survival (DMFS). ${ }^{21}$

\section{Epidermal growth factor receptor}

The EGFR is a transmembrane tyrosine kinase receptor localized on the cell surface that induces cell proliferation, angiogenesis, and apoptosis inhibition. ${ }^{23-25}$ EGFR abnormalities are reported in $27 \%-57 \%$ of TNBCs. ${ }^{26}$ Clinical data suggested a possible predictive and prognostic value of the EGFR. A retrospective analysis of 117 patients, 28 of whom had a TNBC, showed that EGFR expression was related to a worse response to anthracycline-based NST and poor overall prognosis $(p=0.03) .{ }^{27}$ Moreover, in a multivariate analysis of a retrospective study conducted in 287 women with TNBCs, EGFR overexpression was a significant independent prognostic factor for relapse (31\% in EGFR-positive vs $16.2 \%$ in EGFR-negative patients). ${ }^{28}$ Preclinical data showed how the use of anti-EGFR antibodies can decrease antitumor activity by downregulation of EGFR (endocytosis and degradation) and limit cell migration. ${ }^{29}$ Based on this evidence, a multicenter, prospective, single-arm phase II study was conducted among 60 women with stages II and IIIa TNBC, with an aim to investigate the rule of panitumumab (anti-EGFR antibody) in addition to NST (fluorouracil+epirubicin + cyclophosphamide [FEC] followed by docetaxel). ${ }^{12}$ The pCR rates were $46.8 \%$ in breast and nodes, and 55.3\% in the breast only. EGFR expression was confirmed as a predictive factor for response to chemotherapy plus panitumumab. A positive trend for $\mathrm{pCR}$ was shown in EGFR overexpressed BC (58\% vs $28 \%, p=$ 0.079 ), suggesting a potential benefit of anti-EGFR therapy plus chemotherapy in this subgroup of patients. ${ }^{12}$

\section{Tumor-infiltrating lymphocytes}

Since the last decade onward, the immune system has been under investigation as a possible target in the management of different cancer subtypes. Tumor-infiltrated lymphocytes (TILs) have been identified in both tumor and stromal tissues. Intratumoral TILs (It-TILs) are lymphocytes that have a direct interaction with cancer cells, whereas stromal TILs (Str-TILs) 
are lymphocytes localized in the peripheral stromal area. Considering BC subtypes, TNBCs have the highest tumor TIL expression ( $20 \%$ ) compared to other BC subtypes. ${ }^{30,31}$ In particular, the IM subtype of TNBC is characterized by high presence of immune cells, antigen presentation, and activation of immune pathways. ${ }^{21}$ Clinical data suggested a predictive role of TILs in terms of pCR in patients treated with NST, mainly with platinum regimens. ${ }^{32-34}$ A prospective evaluation of TILs in the GeparSixto trial found that lymphocyte-predominant (LP) BC, defined as tumors with lymphocytic infiltrate greater than $50 \%$, were more likely to achieve pCR as compared to non-LP BCs (59.9\% vs $33.8 \%$; $p<0.001) .{ }^{35}$ The addition of carboplatin to anthracycline and taxane in LPBCs further increased the pCR rate up to $75 \%$ $(p=0.002) .{ }^{35}$ The predictive role of TILs primarily suggested by some small retrospective data ${ }^{36-39}$ was confirmed by the large meta-analysis present at the SABCS 2016, where a total of 3,771 tumors from the clinical Gepar studies (GeparDuo, GeparTrio, GeparQuattro, GeparQuinto, GeparSixto, and GeparSepto) were evaluated for the presence of TIL. ${ }^{40}$ These results suggest TILs are a strong predictive marker for response to NST in all BC subtypes. ${ }^{40}$ This predictive value was translated into a survival benefit in the TNBCs group. The presence of TILs in residual tumor disease after primary chemotherapy seems to be related to more favorable long-term outcomes as well. ${ }^{40}$ Another retrospective cohort of 278 patients with TNBCs correlated TIL presence with a risk reduction of metastasis and death. The major prognostic relevance of TILs was found in patients with residual tumor $>2 \mathrm{~cm}$ and/or node metastasis. ${ }^{33}$ These authors hypothesized a possible use of TILs for selecting patients with high risk of relapse after NST. A comparison between TIL expression in the $\mathrm{BC}$ tissue before and after chemotherapy administration was also undertaken, showing that chemotherapy switches low-TIL tumors into high-TIL tumors. ${ }^{33}$ Cytotoxic drugs are able to modify the tumor microenvironment, thus inducing cross-presentation of new peptide antigens, dendritic cell activation, and specific cytotoxic T cells. ${ }^{41-46}$ This evidence supports the idea that the efficacy of immunotherapy may be amplified by chemotherapy. ${ }^{33}$ Based on these data, several neoadjuvant trials studying the addition of immunotherapy to chemotherapy in TNBC patients are ongoing.

Focusing on the subsets of TILs, there are two different functional components: cytotoxic $\mathrm{CD} 8+\mathrm{T}$ cells and regulatory FOXP3+ T cells. CD8+ TILs lead to tumor cell death through linking foreign antigens on tumor cells. ${ }^{47-49}$ In contrast, FOXP3+ TILs, have a critical role in suppressing antitumor immunity. Miyashita et al published a retrospective multicenter study which evaluated CD8+ TIL, FOXP3+ TIL, and CD8/FOXP3 ratios before and after NST in TNBC tissue. ${ }^{50,51}$ The results showed that patients with high CD8+ TILs had a smaller residual tumor $(\leq 2 \mathrm{~cm})$ than patients with low-TILs $(p=0.005) .{ }^{52}$ No association between residual tumor size and FOXP3+ TILs or the CD8/FOXP3 ratio was found. Both high CD8+ levels and higher CD8/FOXP3 ratio were associated with improved recurrence-free survival and breast-cancer-specific survival $(p<0.0001) .{ }^{52}$ These data have been confirmed in a large meta-analysis, where the absence of both CD8+ TILs and FOXP3+ TILs were associated with worse disease-free survival (DFS) and overall survival (OS). ${ }^{53}$

\section{PD-I/PD-LI}

The programmed cell death protein 1 (PD-1) is expressed on the surface of T cells, and is an immune checkpoint that inhibits T-cell effector function within tissues. PD-1 has two ligands known as PD-L1 and PD-L2; in particular, PD-L1 expression is present in several tumor types. The ligand between PD-L1 and PD-1 on the surface of a lymphocyte blocks the immune response against cancer cells. ${ }^{54}$ The presence of PD-L1 in the tumor microenvironment seems to indicate an adaptive immune resistance to endogenous antitumor activity. ${ }^{55}$ With regard to $\mathrm{BC}$, PD-L1 expression has been found in $50 \%$ of all BC subtypes. Its expression was mainly associated with high histological grade and negative hormone receptors. ${ }^{56}$ The first study to investigate PD-L1 expression (defined as cell-surface membrane staining $>5 \%$ ) conducted in $\mathrm{BC}$ found a higher PD-L1 expression in TNBCs as compared to non-TNBCs $(p<0.001) .{ }^{57}$ In a large study, PD-L1 expression was found to be positive in $64 \%$ of the cell membrane, $80 \%$ of cytoplasm, and in $93 \%$ of tumor stroma in TNBCs. In these cases, PD-L1 expression was related to better survival outcomes. ${ }^{58}$ Despite this evidence, it is well known that PD-L1 is a dynamic marker that changes rapidly over time. The tumor microenvironment, as well as systemic cytotoxic treatment and radiation, influence the immune system thereby determining PD-L1 expression changes. Therefore, a biopsy at one time point may not accurately reflect the real tumor microenvironment. For this reason, tumor PD-L1 expression can be considered to only reflect an immune-active microenvironment with activated $\mathrm{T}$ cells in an immunocompetent host, and is not an appropriate predictive biomarker to select patients for immunotherapeutic treatment. ${ }^{59}$ Clinical data on the use of anti-PD-1 or antiPD-L1 antibodies in different cancer subtypes showed how response is possible even in patients with low PD1/PD-L1 expression. ${ }^{60-64}$ 


\section{Androgen receptor}

The LAR TNBC is characterized by high androgen receptor (AR) and luminal cytokeratin expression. ${ }^{21}$ Overall, ARs are expressed in $12 \%-36 \%$ of TNBCs. ${ }^{65-68}$ LAR BCs are usually associated with low grade and tumor size, mainly present in postmenopausal women. ${ }^{69}$ Significantly better DFS, RFS, and OS have been reported on comparing LAR to non-LAR TNBCs..$^{21,70,71}$ AR expression seems to be a predictive biomarker for tumor resistance to chemotherapy. When considering neoadjuvant anthracycline/taxane-based chemotherapy, LAR tumors have the lowest pCR rate $(0 \%$ $10 \%$ ) as compared to other TNBCs..$^{21,70,71}$ On the other hand, AR expression could be considered a predictive marker for tumor response to antiandrogen therapies. Several preclinical studies demonstrated the sensitivity of the LAR cell line to antiandrogen medication. ${ }^{21}$ Xenograft studies with the use of bicalutamide or enzalutamide support the hypothesis that anti-androgen therapy may be useful for such tumors. ${ }^{21,72}$ In the metastatic setting, clinical evidence suggested the efficacy of these two drugs in terms of clinical benefit rate and progression-free survival (PFS) in patients with AR-positive BC. ${ }^{10,11}$ A phase IIB study (NCT02689427) conducted in ARpositive TNBCs treated with enzalutamide plus placlitaxel in the neoadjuvant setting is currently ongoing. ${ }^{73}$

\section{Tumor suppressor gene $\mathrm{p} 53$}

In the subgroups of TNBCs, BL tumors often overexpress genes that codify for proteins involved in cell-cycle and DNAdamage response. p53 is a tumor suppressor protein which plays a key role in apoptosis in response to DNA damage. The complex p53-p63 inhibits the activity of Rab7 - a protein involved in the degradation of EGFR which induces cell proliferation, angiogenesis, and inhibits apoptosis. ${ }^{74}$ Available evidence suggests a possible relationship between $p 53$ and $B R C A 1$, with an increased frequency of $p 53$ mutations in $B R C A$-related tumors. ${ }^{3} p 53$-mutated tumors are characterized by aggressive tumor biology with poor differentiation, high tumor grade, and invasiveness. ${ }^{75,76} \mathrm{p} 53$ overexpression seems to be associated with a worse prognosis in terms of OS and DFS, but with higher chemotherapy sensitivity. ${ }^{75,77-80}$ With regard to TNBC, many studies have demonstrated that $p 53$ is mutated in the majority $(60 \%-88 \%)$ of these tumors. ${ }^{81}$ The most frequent $p 53$ mutations in TNBC are missense mutations with single-amino-acid substitution. ${ }^{82}$ Bidard et al showed that a p53+/TNBC tumor treated with anthracyclines/ alkylating agents had a higher probability of achieving $\mathrm{pCR}$ compared to other $\mathrm{p} 53+/ \mathrm{BC}$ subtypes $(p<0.001) .^{83}$

\section{Chemotherapy agents in the neoadjuvant setting}

Cytotoxic chemotherapy is the backbone of TNBC treatment. In a large study evaluating the neoadjuvant setting, Liedtke et al evaluated the response to different neoadjuvant chemotherapy regimens in 1,118 patients with early-stage $\mathrm{BC}$ treated with different drugs. ${ }^{84}$ In the subgroup of TNBC, the pCR rate was higher as compared to that among non-TNBC patients ( $22 \%$ vs $11 \% ; p=0.034)$, independent of chemotherapy regimens. ${ }^{84}$ Actually, the standard of care in the neoadjuvant setting for TNBC is sequential anthracycline-taxane-based chemotherapy. ${ }^{5}$ The $\mathrm{pCR}$ rate of these regimens ranges from $28 \%$ to $36 \%{ }^{84-86}$ To increase the rate of response, different chemotherapeutic strategies have been tested (Table 2).

\section{Weekly nanoparticle-albumin-bound paclitaxel (nab-paclitaxel) instead of weekly paclitaxel}

Available evidence suggests a possible clinical benefit in terms of tumor response due to the introduction of nab-paclitaxel instead of weekly paclitaxel. In the phase III GeparSepto study, pCR was reached in $48 \%$ of TNBC patients treated with weekly nab-paclitaxel $150 \mathrm{mg} / \mathrm{m}^{2}$ versus $26 \%$ of patients treated with weekly paclitaxel $80 \mathrm{mg} / \mathrm{m}^{2}(p=0.00027){ }^{87}$ Of note, the dose of nab-paclitaxel was reduced from 150 to $125 \mathrm{mg} / \mathrm{m}^{2}$ due to the higher incidence of severe sensory neuropathy, without affecting the treatment efficacy ${ }^{87} \mathrm{~A}$ phase III trial (ETNA study) first presented at the the American Society of Clinical Oncology (ASCO) 2016 showed a higher rate of response in the nab-paclitaxel arm compared to the paclitaxel one ( $41.3 \%$ vs $35.5 \%$; $p$-value not statistically significant) ${ }^{88}$ Similar pCR rates have been reported by Kuwayama et al in a subgroup of TNBC patients treated with four cycles of weekly nab-paclitaxel $100 \mathrm{mg} / \mathrm{m}^{2}{ }^{89}$ Moreover, early results from the WSG-ADAPT trial showed a possible advantage in terms of pCR by adding nab-paclitaxel, rather than gemcitabine, to carboplatin (44.5 vs $28.4, p=0.004) .{ }^{22}$ Several clinical trials are currently further investigating the role of nab-paclitaxel in this setting.

\section{Addition of platinum agents}

The hypothesis of an increased efficacy of platinum agents in TNBC is based on the fact that these tumors often show functional $B R C A 1$ alterations that increase the sensitivity to cross-linking agents. ${ }^{90}$ Clinical evidence suggests that the addition of platinum to standard chemotherapy increases 
Table 2 pCR rate due to different chemotherapy regimens reported in published clinical trials in TNBC patients

\begin{tabular}{|c|c|c|c|c|c|}
\hline Study & Study design & TNBC $n$ & Treatment & PCR definition & PCR \% \\
\hline \multicolumn{6}{|l|}{ Anthracycline/taxane } \\
\hline Liedtke et $\mathrm{a}^{84}$ & Prospective & 255 & Taxane + anthracycline + cyclophosphamide + fluorouracil & ypTO/is ypNO & 28 \\
\hline von Minckwitz et a ${ }^{85}$ & Pooled analysis & 742 & Anthracycline + taxane & ypTO/is ypNO & 34 \\
\hline von Minckwitz et a ${ }^{86}$ & Pooled analysis & 911 & Anthracycline + taxane & ypTO/is ypNo & 35.8 \\
\hline \multicolumn{6}{|l|}{ Carboplatin } \\
\hline Sikov et $\mathrm{al}^{95}$ & Phase II & 12 & Paclitaxel + carboplatin & ypTO/is ypNo & 67 \\
\hline Chen et $\mathrm{a}^{96}$ & Phase II & 17 & Paclitaxel + carboplatin & ypTO/is ypNO & 33.3 \\
\hline Roy et $\mathrm{al}^{97}$ & Phase II & 9 & Docetaxel + carboplatin & урT0 yрN0 & 44 \\
\hline Chang et $\mathrm{a}^{98}$ & Phase II & 11 & Docetaxel + carboplatin & ypTO/is ypNO & 55 \\
\hline Campos Gomez et al99 & Phase II & 35 & $\begin{array}{l}\text { Doxorubicin }+ \text { cyclophosphamide } \rightarrow \text { docetaxel }+ \\
\text { carboplatin }\end{array}$ & yрT0/is ypN0 & 50 \\
\hline Von Minckwitz et al ${ }^{100}$ & Phase III & 158 & $\begin{array}{l}\text { Paclitaxel + liposomal doxorubicin + bevacizumab + } \\
\text { carboplatin }\end{array}$ & yрT0 yрN0 & 53.2 \\
\hline \multicolumn{6}{|l|}{ Nab-paclitaxel } \\
\hline Untch et $\mathrm{a}^{87}$ & Phase III & 139 & Nab-paclitaxel $\rightarrow$ epirubicin + cyclophosphamide & урT0 урN0 & 48 \\
\hline Gianni et $a^{88}$ & Phase III & 219 & Nab-paclitaxel + anthracycline (investigator choice) & ypTO/is ypNO & 41.3 \\
\hline Gluz et $\mathrm{a}^{22}$ & Phase II & 61 & Nab-paclitaxel + carboplatin & ypTO/is ypNo & 49.2 \\
\hline Kuwayama et a ${ }^{89}$ & Phase II & 54 & $\begin{array}{l}\text { Nab-paclitaxel }+ \text { anthracycline }+ \text { cyclophosphamide }+ \\
\text { fluorouracil }\end{array}$ & ypTO/is ypNo & 30 \\
\hline \multicolumn{6}{|l|}{ Eribulin } \\
\hline Kaklamani et al ${ }^{102}$ & Phase II & 30 & Carboplatin + eribulin & ypTO/is ypNo & 43 \\
\hline
\end{tabular}

Abbreviations: TNBC, triple negative breast cancer; PCR, pathological complete response; Nab-paclitaxel, nanoparticle-albumin-bound paclitaxel.

the rate of tumor response, but this clinical advantage has not been clearly translated into a survival benefit. Platinumbased chemotherapy has been investigated in several studies, but the best platinum agent, the ideal combination, or the best sequence with other chemotherapy agents remains unknown. ${ }^{91-93}$ In particular, a retrospective study that compared docetaxel with cisplatin or carboplatin showed the superiority of cisplatin in terms of OS (hazard ratio [HR] $0.49, p=0.007$ ) and PFS (HR $0.40, p=0.018$ ) with a quite good tolerability profile. ${ }^{92}$ This difference between the two platinum agents was not confirmed in another large pooled analysis. ${ }^{94}$ More consistent are the data on the increased response rate due to the addition of platinum to standard chemotherapy, mainly in anthracycline-free regimens. ${ }^{95-98}$ The subgroup analysis of five clinical trials, conducted in TNBC patients treated with neoadjuvant platinum-containing therapies combined with taxanes, showed a pCR rate ranging from $33 \%$ to $67 \%{ }^{95-99}$ These data are in accordance with the results from the GeparSixto study, where the addition of carboplatin to anthracycline or taxane-based therapy improved the pCR from $36.9 \%$ to $53.2 \%{ }^{100} \mathrm{~A}$ large meta-analysis (included six randomized controlled trials and 22 retrospective or prospective studies) strongly confirmed the advantage due to platinum addition in both the objective response rate (86.7\%) and the pCR rate (48.4\%). ${ }^{94}$ Data presented at the ASCO 2017 further underline the advantage in tumor response in patients treated with carboplatin/docetaxel compared to taxane-anthracycline-based regimen. ${ }^{101}$ Data from the WSG-
ADAPT TN trial suggested that immune marker gene expression (CD8, PD1, and PFDL1) and high-proliferation markers (proliferation score, Prosigna Breast Cancer Prognostic Gene Signature Assay [PAM-50] risk-of-recurrence [ROR] score, MKI67, CDC20, NUF2, KIF2C, CENPF, EMP3, and TYMS) were positively associated with $\mathrm{pCR}$ in carbo-containing chemotherapy regimens. ${ }^{22}$ In all of these reported studies, the addition of carboplatin increased hematological and non-hematological toxicity, with consequent frequent dose reduction. Nowadays, the increased toxicity and the lack of clear demonstrated long-term survival benefit due to platinum addition constitute reasons why platinum agents are not included in the standard of care for TNBC in the neoadjuvant setting. Despite this, the evidence that the $\mathrm{pCR}$ is strongly associated with OS in TNBC is an argument often used by the physicians to justify the addition of carboplatin to NST in clinical practice. Several phase III trials are ongoing and may provide more information on this topic.

\section{Eribulin in addition to carboplatin}

Eribulin is a non-taxane microtubule inhibitor that causes irreversible cell-cycle blockade at the G2-M phase. Eribulin is approved in the management of metastatic $\mathrm{BC}$ after at least two treatment regimens with an anthracycline and a taxane, but its role in other settings is currently under investigation. A phase II clinical trial conducted in $30 \mathrm{TN}$ early-stage $\mathrm{BC}$ patients investigated the response rate to 3-weekly carboplatin AUC 6 plus eribulin $1.4 \mathrm{mg} / \mathrm{m}^{2}$ (days 1 and 8 every 21 days). ${ }^{102} \mathrm{In}$ 
total, $80 \%$ of enrolled patients had a clinical complete or partial response, and $43 \%$ achieved pCR. ${ }^{102}$ Moreover, another phase II international trial (NCT01372579) is ongoing with the aim to investigate the efficacy of a preoperative eribulin mesylate and carboplatin combination in stages I-III TNBCs. ${ }^{103}$

\section{Dose-dense chemotherapy}

Dose-dense (DD) chemotherapy aims to achieve maximum tumor death by delivering therapeutic drugs over a shorter duration. The efficacy of DD systemic treatment was mainly investigated in the adjuvant setting. A recent meta-analysis including a total of eight phase III trials $(17,188$ randomized women) showed that patients treated with DD chemotherapy had better OS and DFS than those on the conventional schedule. In particular, statistically significant OS benefit was observed in patients with hormone-receptor-negative tumors (HR 0.8, $p=0.002$ ). ${ }^{104}$ Data from the DD schedule in the neoadjuvant setting are less consistent. ${ }^{105}$ Published clinical trials included women treated with outdated regimens and/ or schedules; there are no data regarding the benefit of DD anthracycline-taxane-based primary chemotherapy. Conventionally, in clinical practice, results from DD adjuvant chemotherapy studies are applied in the neoadjuvant setting too.

\section{Targeted agents tested in neoadjuvant setting}

Table 3 summarizes the main clinical trials where targeted agents have been evaluated in addition to NST.

\section{PARP-I inhibitors}

PARP-1 is an enzyme known to be involved in the baseexcision repair pathway, which plays a key role in the repair of single-stranded DNA breaks. ${ }^{106,107}$ During the last decade, drugs able to interfere with the DNA-damage-repair systems and to induce a synthetic lethality, named PARP inhibitors (such as iniparib, olaparib, and veliparib), have been developed. The main evidence is in the metastatic setting, where PARP inhibitors have been tested as single agents and in combination with chemotherapy. ${ }^{9,108}$ The best results in terms of efficacy emerged from combination with cisplatin or carboplatin, as well as with topotecan and temozolamide, with response rates in BRCA-related BC of up to $73 \% .{ }^{109-112}$ Considering the use of PARP inhibitors in the neoadjuvant setting, a single-arm phase II study showed efficacy in terms of pCR of gemcitabine combined with carboplatin and iniparib in TNBC. ${ }^{113}$ In this study, the presence of HRD was associated with higher response rates, regardless of $B R C A 1 / 2$ mutational status. ${ }^{113}$ Results from the veliparib and carboplatin arm in the I-SPY-2 trial, a multicenter, adaptively randomized trial, reported 51\% pCR in the experimental arm versus $26 \%$ in the standard regimen. Considering adverse events, hematological side effects were higher in the veliparib-carboplatin group than in the control arm. ${ }^{114}$ No difference in the pCR rate due to the addition of velaparib to carboplatin-paclitaxel, followed by doxorubicin plus cyclophosphamide, has been reported in a phase III study presented by the German Breast Group at the ASCO 2017. ${ }^{115}$ A phase II study of neoadjuvant talazoparib monotherapy in BRCA-associated BC is ongoing at the MD Anderson Cancer Center. ${ }^{116}$ Considering these preliminary controversial results, PARP inhibitors are still under investigation.

\section{Anti-angiogenic agents}

Bevacizumab is a humanized monoclonal antibody that targets the main isoforms of circulating vascular endothelial

Table 3 pCR rate TNBC patients treated with chemotherapy plus targeted agents

\begin{tabular}{|c|c|c|c|c|c|}
\hline Study & Study design & TNBC $n$ & Treatment & pCR definition & pCR \% \\
\hline \multicolumn{6}{|l|}{ Bevacizumab } \\
\hline Gerber et $\mathrm{al}^{7}$ & Phase III & 323 & Epirubicin + cyclophosphamide $\rightarrow$ docetaxel + bevacizumab & урT0 урN0 & 39 \\
\hline Earl et $\mathrm{al}^{|2|}$ & Phase III & 119 & Bevacizumab + docetaxel $\rightarrow$ epirubicin + cyclophosphamide & yрT0/is ypNo & 45 \\
\hline Sikov et al ${ }^{122}$ & Phase II & 226 & Paclitaxel $\rightarrow$ doxorubicin + cyclophosphamide + bevacizumab & ypT0/is* & 59 \\
\hline Guarneri et al ${ }^{124}$ & Phase II & 44 & Paclitaxel + carboplatin + bevacizumab & yрT0/is ypNo & 50 \\
\hline Kim et al $^{125}$ & Phase II & 45 & Carboplatin + docetaxel + bevacizumab & yрT0/is ypNo & 42 \\
\hline Nahleh et al ${ }^{126}$ & Phase II & 32 & Nab-paclitaxel + bevacizumab $\rightarrow$ adriamycin + cyclophosphamide & yрT0/is ypNo & 59 \\
\hline Mrózek et al ${ }^{127}$ & Phase II & 12 & Nab-paclitaxel + carboplatin + bevacizumab & урT0 урN0 & 50 \\
\hline \multicolumn{6}{|l|}{ PARP-inhibitor } \\
\hline Telli et al ${ }^{1 / 3}$ & Phase II & 80 & Gemcitabine + carboplatin + iniparib ${ }^{\S}$ & ypTO/is ypNo & 36 \\
\hline Rugo et al $^{1 / 4}$ & Phase II & 54 & Velparib + carboplatin $\rightarrow$ doxorubicin + cyclophosphamide & урТ0 урN0 & 51 \\
\hline \multicolumn{6}{|l|}{ Immunotherapy } \\
\hline Schmid et al ${ }^{128}$ & Phase IB & 20 & $\begin{array}{l}\text { Pembrolizumab }+ \text { nab-paclitaxel } \rightarrow \text { pembrolizumab }+ \text { doxorubicin } \\
+ \text { cyclophosphamide } \pm \text { carboplatin }\end{array}$ & ypTO/is ypNo & 85 \\
\hline Nanda et al ${ }^{129}$ & Phase II & 21 & Paclitaxel + pembrolizumab $\rightarrow$ doxorubicin + cyclophosphamide & ypTO/is ypNo & 71 \\
\hline
\end{tabular}

Note: ${ }^{\mathrm{p} C R}$ in breast only; ${ }^{\S} \mathrm{pCR}$ rate in patients treated with six cycles of neoadjuvant treatment.

Abbreviations: TNBC, triple negative breast cancer; PCR, pathological complete response. 
growth factor (VEGF), resulting in the inhibition of angiogenesis, cell tumor growth, and cell survival. ${ }^{117}$ Bevacizumab use has been investigated in both advanced and early-stage BC treatments, showing an increased response rate - mainly, in TNBC patients. ${ }^{84,100,118-120}$ When added to chemotherapy in preoperative treatment, the $\mathrm{pCR}$ rate ranges from $40 \%$ to $59 \%$ independent of the chemotherapy regimen administered. The phase III GeparQuinto trial included 663 TNBC patients treated with epirubicin and cyclophosphamide followed by docetaxel with or without bevacizumab, and showed a pCR rate of $39.3 \%$ in the bevacizumab arm versus $27.9 \%$ in the control arm $(p=0.021) .{ }^{7}$ The advantage in response rate due to the addition of bevacizumab has been demonstrated in two other large trials. The first one is the multicenter British phase III study (ARTemis), where 781 patients were randomized to receive bevacizumab or placebo plus docetaxel followed by cyclophosphamide, 5-fluorouracil, and epirubicine. ${ }^{121}$ In the TNBC subgroup, bevacizumab provided an advantage in terms of pCR from $34 \%$ to $49 \%$. ${ }^{121}$ The second one - the CALGB 40603/Alliance trial, conducted in 443 patients with stages II and III TNBC - confirmed the increase of tumor response in the bevacizumab group, independent of the chemotherapy regimen administered. ${ }^{122,123}$ Similar response rates have been found in two phase II trials: the Ca.Pa.Be study, where 44 TNBC women were treated with a combination of paclitaxel, carboplatin, and bevacizumab, and the KCSG BR-0905 trial, where 45 women were treated with bevacizumab, docetaxel, and carboplatin. ${ }^{124,125}$ The addition of bevacizumab to nab-paclitaxel was investigated in two phase II trials, showing an increase of response rate compared to bevacizumab plus paclitaxel or docetaxel. ${ }^{126,127}$ In the first one, the SWOG S0800 trial, the combination of bevacizumab plus nab-paclitaxel, followed by DD doxorubicin and cyclophosphamide, increased the pCR rate up to $59 \%(p=0.014) .{ }^{126}$ In the second one, $50 \%$ of TNBC patients treated with bevacizumab plus nab-paclitaxel and carboplatin achieved pCR. ${ }^{127}$ With regard to safety profile, patients treated with bevacizumab experienced an increased number of immediate and delayed postoperative complications as well as neutropenia and hypertension. ${ }^{121,122}$ Nowadays, the use of bevacizumab in the neoadjuvant setting is still controversial and not recommended, mainly due to the lack of survivalbenefit evidence.

\section{Immunotherapy}

The evidence that stimulating the immune cells might, therefore, be an option to increase response rates is the rationale for designing clinical trials with the addition of immunotherapy in the neoadjuvant setting. Preliminary results from the KEYNOTE-173 presented at the ASCO 2017 (nab-paclitaxel \pm carboplatin plus pembrolizumab, followed by cyclophosphamide and doxorubicin) suggested promising antitumor activity of pembrolizumab when combined with NST. ${ }^{128}$

The objective response rate before surgery was $100 \%$ in the pembrolizumab and carboplatin group versus $80 \%$ in the other experimental group (nab-paclitaxel + pembrolizumab); the $\mathrm{pCR}$ rate (yT0/Tis yN0) was $90 \%$ versus $60 \%$, respectively. ${ }^{128}$ Similar results have been reported in the subgroup of patients treated with pembrolizumab in the I-SPY-2 trial. ${ }^{129}$ Data presented at the ASCO 2017 were based on results observed in patients at high risk of relapse using upfront tumor profiling (including mammaPrint 70-gene signature test). Patients were treated with weekly paclitaxel for 12 weeks \pm pembrolizumab, followed by anthracyclines. ${ }^{129}$ In the TNBC women, an absolute increase in the estimated pCR rate of $40 \%$ was observed in the pembrolizumab arm (based on the estimated pCR rate of $60 \%$ with pembrolizumab plus standard therapy compared to $20 \%$ with standard NST alone). ${ }^{129}$ Currently, two different strategies are under investigation to evaluate the real benefit of immunotherapy in early-stage TNBC: the addition of PD1/PD-L1 inhibitors to different NST regimens and the administration of $\mathrm{PD} 1 / \mathrm{PD}-\mathrm{L} 1$ inhibitors in the adjuvant setting in patients with residual $\mathrm{BC}$ disease after NST. In the first case, four studies are currently recruiting patients: the phase III NeoTRIPaPDL1 trial, a multicenter randomized study with patients treated with nab-paclitaxel plus carboplatin \pm atezolizumab; ${ }^{130}$ the GeparNuevo trial, a phase II study of nab-paclitaxel \pm durvalumab followed by epirubicin plus cyclophosphamide; and two other studies with nab-paclitaxel plus atezolizumab or durvalumab. ${ }^{131-133}$ With regard to the second strategy, two big clinical trials are now ongoing, both conducted in high-risk TNBC patients with residual disease after NST, randomized to receive 1 year of adjuvant pembrolizumab or avelumab versus observation. ${ }^{134,135}$ The results of all these studies are awaited with high interest.

\section{Conclusion}

According to current international guidelines, in early-stage TNBC, the timing of treatment (pre- vs postoperative) has no effect on long-term outcomes. All chemotherapy strategies used in adjuvant treatment may also be used preoperatively. If a primary chemotherapy treatment is used, it is recommended to deliver all planned treatment without unnecessary breaks, irrespective of the magnitude of tumor response. ${ }^{136,137}$

In our opinion, NST should be the first option in the case of operable TNBC, especially in locally advanced cases 
(when mastectomy is required due to tumor size), as well as in high-grade and high-proliferation-rate tumors. Despite the progress in our understanding of TNBC, anthracyclinetaxane-based chemotherapy remains the standard of care for NST in all TNBC subtypes. Platinum agents, as well as PARP-inhibitor agents, provide $\mathrm{pCR}$ advantage in different clinical trials, mainly in BRCA-defense tumors, without demonstrating an improvement in survival benefit. At present, there are no clear predictive biomarkers useful in clinical practice. The classification of TNBC using molecular profile showed how TNBCs are a heterogeneous group which explains the lack of survival benefit of experimental drugs tested in several clinical trials. All of the available evidence suggests the necessity of design biology-driven clinical trials wherein TNBC patients may be treated on the basis of tumor molecular profile.

\section{Acknowledgment}

This research received no specific grant from any funding agency in the public, commercial, or not-for-profit sectors.

\section{Disclosure}

The authors report no conflicts of interest in this work.

\section{References}

1. Esteller M. Epigenetics in cancer. N Engl J Med. 2008;358(11): $1148-1159$.

2. Kennedy RD, Quinn JE, Johnston PG, Harkin DP. BRCA1: mechanisms of inactivation and implications for management of patients. Lancet. 2002;360(9338):1007-1014.

3. Birgisdottir V, Stefansson OA, Bodvarsdottir SK, Hilmarsdottir $\mathrm{H}$, Jonasson JG, Eyfjord JE. Epigenetic silencing and deletion of the BRCA1 gene in sporadic breast cancer. Breast Cancer Res. 2006;8(4):R38.

4. Balmaña J, Díez O, Rubio IT, Cardoso F; ESMO Guidelines Working Group. BRCA in breast cancer: ESMO clinical practice guidelines. Ann Oncol. 2011;22 (Suppl 6):vi31-vi34.

5. Senkus E, Kyriakides S, Ohno S, et al; ESMO Guidelines Committee. Primary breast cancer: ESMO Clinical Practice Guidelines for diagnosis, treatment and follow-up. Ann Oncol. 2015;26(Suppl 5):v8-v30.

6. Huober J, von Minckwitz G, Denkert C, et al. Effect of neoadjuvant anthracycline-taxane-based chemotherapy in different biological breast cancer phenotypes: overall results from the GeparTrio study. Breast Cancer Res Treat. 2010;124(1):133-140.

7. Gerber B, Loibl S, Eidtmann H, et al; German Breast Group Investigators. Neoadjuvant bevacizumab and anthracycline-taxane-based chemotherapy in 678 triple-negative primary breast cancers; results from the geparquinto study (GBG 44). Ann Oncol. 2013;24(12):2978-2984.

8. Yardley DA, Shipley DL, Peacock NW, et al. Phase I/II trial of neoadjuvant sunitinib administered with weekly paclitaxel/carboplatin in patients with locally advanced triple-negative breast cancer. Breast Cancer Res Treat. 2015;152(3):557-567.

9. Tutt A, Robson M, Garber JE, et al. Oral poly(ADP-ribose) polymerase inhibitor olaparib in patients with BRCA1 or BRCA2 mutations and advanced breast cancer: a proof-of-concept trial. Lancet 2010;376(9737):235-244.
10. Gucalp A, Tolaney S, Isakoff SJ, et al; Translational Breast Cancer Research Consortium (TBCRC 011). Phase II Trial of bicalutamide in patients with androgen receptor-positive, estrogen receptor-negative metastatic breast cancer. Clin Cancer Res. 2013;19(19):5505-5512.

11. Traina TA, Miller K, Yardley DA, et al. Results from a phase 2 study of enzalutamide (ENZA), an androgen receptor (AR) inhibitor, in advanced AR+ triple-negative breast cancer (TNBC). J Clin Oncol. 2015;33(Suppl 15):abstract 1003.

12. Nabholtz JM, Abrial C, Mouret-Reynier MA, et al. Multicentric neoadjuvant phase II study of panitumumab combined with an anthracycline/ taxane-based chemotherapy in operable triple-negative breast cancer: identification of biologically defined signatures predicting treatment impact. Ann Oncol. 2014;25(8):1570-1577.

13. Haffty BG, Yang Q, Reiss M, et al. Locoregional relapse and distant metastasis in conservatively managed triple negative early-stage breast cancer. J Clin Oncol. 2006;24(36):5652-5657.

14. D'Andrea AD, Grompe M. The Fanconi anaemia/BRCA pathway. Nat Rev Cancer. 2003;3(1):23-34.

15. Byrski T, Huzarski T, Dent R, et al. Pathologic complete response to neoadjuvant cisplatin in BRCA1-positive breast cancer patients. Breast Cancer Res Treat. 2014;147(2):401-405.

16. Wang C, Zhang J, Wang Y, et al. Prevalence of BRCA1 mutations and responses to neoadjuvant chemotherapy among BRCA1 carriers and non-carriers with triple-negative breast cancer. Ann Oncol. 2015;26(3):523-528.

17. Farmer H, McCabe N, Lord CJ, et al. Targeting the DNA repair defect in BRCA mutant cells as a therapeutic strategy. Nature. 2005;434(7035): 917-921.

18. Silver DP, Richardson AL, Eklund AC, et al. Efficacy of neoadjuvant Cisplatin in triple-negative breast cancer. J Clin Oncol. 2010;28(7): $1145-1153$.

19. Chabalier C, Lamare C, Racca C, Privat M, Valette A, Larminat F. BRCA1 downregulation leads to premature inactivation of spindle checkpoint and confers paclitaxel resistance. Cell Cycle. 2006;5(9):1001-1007.

20. Telli ML, Timms KM, Reid J et al. Homologous recombination deficiency (HRD) as a predictive biomarkers of response to neoadjuvant platinum-based therapy in patients with triple negative breast cancer. Cancer Res. 2016;76(4 Suppl):P3-07-12.

21. Lehmann BD, Bauer JA, Chen X, et al. Identification of human triplenegative breast cancer subtypes and preclinical models for selection of targeted therapies. J Clin Invest. 2011;121(7):2750-2767.

22. Gluz O, Nitz U, Liedtke $C$, et al. Comparison of 12 weeks neoadjuvant Nab-paclitaxel combined with carboplatinum vs. gemcitabine in triplenegative breast cancer: WSG-ADAPT TN randomized phase II trial. Cancer Res. 2016;76(4 Suppl): Abstract nr S6-07.

23. Herbst RS. Review of epidermal growth factor receptor biology. Int J Radiat Oncol Biol Phys. 2004;59(2 Suppl):21-26.

24. Zhang H, Berezov A, Wang Q, et al. ErbB receptors: from oncogenes to targeted cancer therapies. J Clin Invest. 2007;117(8):2051-2058.

25. Siziopikou KP, Cobleigh M. The basal subtype of breast carcinomas may represent the group of breast tumors that could benefit from EGFR-targeted therapies. Breast. 2007;16(1):104-107.

26. Bidard FC, Conforti R, Boulet T, Michiels S, Delaloge S, André F. Does triple-negative phenotype accurately identify basal-like tumour? An immunohistochemical analysis based on 143 'triple-negative' breast cancers. Ann Oncol. 2007;18(7):1285-1286.

27. Nogi H, Kobayashi T, Suzuki M, et al. EGFR as paradoxical predictor of chemosensitivity and outcome among triple-negative breast cancer. Oncol Rep. 2009;21(2):413-417.

28. Liu D, He J, Yuan Z, et al. EGFR expression correlates with decreased disease-free survival in triple negative breast cancer: a retrospective analysis based on a tissue microarray. Med Oncol. 2012;29(2):401-405.

29. Ferraro DA, Gaborit N, Maron R, et al. Inhibition of triple-negative breast cancer models by combinations of antibodies to EGFR. Proc Natl Acad Sci U S A. 2013;110(5):1815-1820. 
30. Disis ML, Stanton SE. Triple-negative breast cancer: immune modulation as the new treatment paradigm. Am Soc Clin Oncol Educ Book. 2015:e25-e30.

31. García-Teijido P, Cabal ML, Fernández IP, Pérez YF. Tumor-infiltrating lymphocytes in triple negative breast cancer: the future of immune targeting. Clin Med Insights Oncol. 2016;10(Suppl 1):31-39.

32. Denkert C, Loibl S, Noske A, et al. Tumor-associated lymphocytes as an independent predictor of response to neoadjuvant chemotherapy in breast cancer. J Clin Oncol. 2010;28(1):105-113.

33. Dieci MV, Criscitiello C, Goubar A, et al. Prognostic value of tumorinfiltrating lymphocytes on residual disease after primary chemotherapy for triple-negative breast cancer: a retrospective multicenter study. Ann Oncol. 2014;25(3):611-618.

34. Vinayak S, Gray RJ, Adams S, et al. Association of increased tumor-infiltrating lymphocytes (TILs) with immunomodulatory (IM) triple-negative breast cancer (TNBC) subtype and response to neoadjuvant platinumbased therapy in PrECOG0105. J Clin Oncol. 2014;32(Suppl 15): abstract 1000 .

35. Salgado R, Denkert C, Demaria S, et al; International TILs Working Group 2014. The evaluation of tumor-infiltrating lymphocytes (TILS) in breast cancer: Recommendations by an International TILS Working Group 2014. Ann Oncol. 2015;26(2):259-271.

36. Pruneri G, Vingiani A, Bagnardi V, et al. Clinical validity of tumorinfiltrating lymphocytes analysis in patients with triple-negative breast cancer. Ann Oncol. 2016;27(2):249-256

37. Loi S, Michiels S, Salgado R, et al. Tumor infiltrating lymphocytes are prognostic in triple negative breast cancer and predictive for trastuzumab benefit in early breast cancer: results from the FinHER trial. Ann Oncol. 2014;25(8):1544-1550.

38. Adams S, Gray RJ, Demaria S, et al. Prognostic value of tumorinfiltrating lymphocytes in triple-negative breast cancers from two phase III randomized adjuvant breast cancer trials: ECOG 2197 and ECOG 1199. J Clin Oncol. 2014;32(27):2959-2966.

39. Cimino-Mathews A, Foote JB, Emens LA. Immune targeting in breast cancer. Oncology (Williston Park). 2015;29(5):375-385.

40. Denkert C, von Minckwitz G, Darb-Esfahani S, et al. Evaluation of tumor-infiltrating lymphocytes (TILs) as predictive and prognostic biomarker in different subtypes of breast cancer treated with neoadjuvant therapy - a metaanalysis of 3771 patients. Cancer Res. 2017; 77(4 Suppl):Abstract nr S1-09.

41. Zitvogel L, Apetoh L, Ghiringhelli F, André F, Tesniere A, Kroemer $\mathrm{G}$. The anticancer immune response: indispensable for therapeutic success? J Clin Invest. 2008;118(6):1991-2001.

42. Roselli M, Cereda V, di Bari MG, et al. Effects of conventional therapeutic interventions on the number and function of regulatory $\mathrm{T}$ cells. Oncoimmunology. 2013;2(10):e27025.

43. Jäger D, Jäger E, Knuth A. Immune responses to tumour antigens: implications for antigen specific immunotherapy of cancer. J Clin Pathol. 2001;54(9):669-674.

44. Schreiber RD, Old LJ, Smyth MJ. Cancer immunoediting: integrating immunity's roles in cancer suppression and promotion. Science. 2011;331(6024):1565-1570.

45. Apetoh L, Ghiringhelli F, Tesniere A, et al. Toll-like receptor 4-dependent contribution of the immune system to anticancer chemotherapy and radiotherapy. Nat Med. 2007;13(9):1050-1059.

46. Andre F, Dieci MV, Dubsky P, et al. Molecular pathways: involvement of immune pathways in the therapeutic response and outcome in breast cancer. Clin Cancer Res. 2013;19(1):28-33.

47. Berke G. The binding and lysis of target cells by cytotoxic lymphocytes: molecular and cellular aspects. Annu Rev Immunol. 1994;12: 735-773.

48. Segal NH, Parsons DW, Peggs KS, et al. Epitope landscape in breast and colorectal cancer. Cancer Res. 2008;68(3):889-892.

49. Zitvogel L, Kepp O, Kroemer G. Immune parameters affecting the efficacy of chemotherapeutic regimens. Nat Rev Clin Oncol. 2011;8(3): $151-160$
50. Liyanage UK, Moore TT, Joo HG, et al. Prevalence of regulatory T cells is increased in peripheral blood and tumor microenvironment of patients with pancreas or breast adenocarcinoma. J Immunol. 2002;169(5):2756-2761.

51. Viguier M, Lemaître F, Verola O, et al. Foxp3 expressing CD4+CD25(high) regulatory $\mathrm{T}$ cells are overrepresented in human metastatic melanoma lymph nodes and inhibit the function of infiltrating T cells. J Immunol. 2004;173(2):1444-1453.

52. Miyashita M, Sasano H, Tamaki K, et al. Prognostic significance of tumor-infiltrating CD8+ and FOXP3+ lymphocytes in residual tumors and alterations in these parameters after neoadjuvant chemotherapy in triple-negative breast cancer: a retrospective multicenter study. Breast Cancer Res. 2015;17:124.

53. Ibrahim EM, Al-Foheidi ME, Al-Mansour MM, Kazkaz GA. The prognostic value of tumor-infiltrating lymphocytes in triple-negative breast cancer: a meta-analysis. Breast Cancer Res Treat. 2014;148(3):467-476.

54. Pardoll DM. The blockade of immune checkpoints in cancer immunotherapy. Nat Rev Cancer. 2012;12(4):252-264.

55. Wimberly H, Brown JR, Schalper K, et al. PD-L1 expression correlates with tumor-infiltrating lymphocytes and response to neoadjuvant chemotherapy in breast cancer. Cancer Immunol Res. 2015;3(4):326-332.

56. Ghebeh H, Mohammed S, Al-Omair A, et al. The B7-H1 (PD-L1) T lymphocyte-inhibitory molecule is expressed in breast cancer patients with infiltrating ductal carcinoma: correlation with important high-risk prognostic factors. Neoplasia. 2006;8(3):190-198.

57. Mittendorf EA, Philips AV, Meric-Bernstam F, et al. PD-L1 expression in triple-negative breast cancer. Cancer Immunol Res. 2014;2(4):361-370.

58. Beckers RK, Selinger CI, Vilain R, et al. Programmed death ligand 1 expression in triple-negative breast cancer is associated with tumourinfiltrating lymphocytes and improved outcome. Histopathology. 2016;69(1):25-34

59. Meng X, Huang Z, Teng F, Xing L, Yu J. Predictive biomarkers in PD-1/PD-L1 checkpoint blockade immunotherapy. Cancer Treat Rev. 2015;41(10):868-876

60. Robert C, Long GV, Brady B, et al. Nivolumab in previously untreated melanoma without BRAF mutation. $N$ Engl J Med. 2015;372(4):320-330.

61. Brahmer J, Reckamp KL, Baas P, et al. Nivolumab versus docetaxel in advanced squamous-cell non-small-cell lung cancer. $N$ Engl J Med. 2015;373(2):123-135.

62. Borghaei H, Paz-Ares L, Horn L, et al. Nivolumab versus docetaxel in advanced nonsquamous non-small-cell lung cancer. $N$ Engl J Med. 2015;373(17):1627-1639.

63. Motzer RJ, Escudier B, McDermott DF, et al; CheckMate 025 Investigators. Nivolumab versus everolimus in advanced renal-cell carcinoma. N Engl J Med. 2015;373(19):1803-1813.

64. Ferris RL, Blumenschein G Jr, Fayette J, et al. Nivolumab for recurrent squamous-cell carcinoma of the head and neck. $N$ Engl J Med. 2016;375(19):1856-1867.

65. Collins LC, Cole Ks, Marotti JD, Hu R, Schnitt SJ, Tamimi RM. Androgen receptor expression in breast cancer in relation to molecular phenotype: results from the Nurses' Health Study. Mod Pathol. 2011;24(7):924-931.

66. Mrklić I, Pogorelić Z, Capkun V, Tomić S. Expression of androgen receptors in triple negative breast carcinomas. Acta Histochem. 2013;115(4):344-348.

67. Thike AA, Yong-Zheng Chong L, Cheok PY, et al. Loss of androgen receptor expression predicts early recurrence in triple-negative and basal-like breast cancer. Mod Pathol. 2014;27(3):352-360.

68. Safarpour D, Pakneshan S, Tavassoli FA. Androgen receptor (AR) expression in 400 breast carcinomas: is routine AR assessment justified? Am J Cancer Res. 2014;4(4):353-368. eCollection 2014.

69. Agoff SN, Swanson PE, Linden H, Hawes SE, Lawton TJ. Androgen receptor expression in estrogen receptor-negative breast cancer. Immunohistochemical, clinical, and prognostic associations. Am J Clin Pathol. 2003;120(5):725-731. 
70. Park S, Koo J, Park HS, et al. Expression of androgen receptors in primary breast cancer. Ann Oncol. 2010;21(3):488-492.

71. Masuda H, Baggerly KA, Wang Y, et al. Differential response to neoadjuvant chemotherapy among 7 triple-negative breast cancer molecular subtypes. Clin Cancer Res. 2013;19(19):5533-5540.

72. Cochrane DR, Bernales S, Jacobsen BM, et al. Role of the androgen receptor in breast cancer and preclinical analysis of enzalutamide. Breast Cancer Res. 2014;16(1):R7.

73. M. D. Anderson Cancer Center. Phase IIB neoadjuvant enzalutamide (ZT) plus taxol for androgen receptor (AR)-positive triple-negative breast cancer (AR+TNBC). Available from: https://clinicaltrials.gov/ ct2/show/NCT02689427. NLM identifier: NCT02689427. Accessed December 8, 2017.

74. Ceresa BP, Bahr SJ. rab7 activity affects epidermal growth factor: epidermal growth factor receptor degradation by regulating endocytic trafficking from the late endosome. J Biol Chem. 2006;281(2):1099-1106.

75. Guarneri V, Barbieri E, Piacentini F, et al. Predictive and prognostic role of p53 according to tumor phenotype in breast cancer patients treated with preoperative chemotherapy: a single-institution analysis. Int J Biol Markers. 2010;25(2):104-111.

76. Yadav BS, Chanana P, Jhamb S. Biomarkers in triple negative breast cancer: a review. World J Clin Oncol. 2015;6(6):252-263.

77. Han JS, Cao D, Molberg KH, et al. Hormone receptor status rather than HER2 status is significantly associated with increased $\mathrm{Ki}-67$ and p53 expression in triple-negative breast carcinomas, and high expression of Ki-67 but not p53 is significantly associated with axillary nodal metastasis in triple-negative and high-grade non-triple-negative breast carcinomas. Am J Clin Pathol. 2011;135(2):230-237.

78. Langerød A, Zhao H, Borgan Ø, et al. TP53 mutation status and gene expression profiles are powerful prognostic markers of breast cancer. Breast Cancer Res. 2007;9(3):R30.

79. Miller LD, Smeds J, George J, et al. An expression signature for $\mathrm{p} 53$ status in human breast cancer predicts mutation status, transcriptional effects, and patient survival. Proc Natl Acad Sci U SA. 2005;102(38): 13550-13555.

80. Biganzoli E, Coradini D, Ambrogi F, et al. p53 status identifies two subgroups of triple-negative breast cancers with distinct biological features. Jpn J Clin Oncol. 2011;41(2):172-179.

81. Turner N, Moretti E, Siclari O, et al. Targeting triple negative breast cancer: is p53 the answer? Cancer Treat Rev. 2013;39(5):541-550.

82. Walerych D, Napoli M, Collavin L, Del Sal G. The rebel angel: mutant p53 as the driving oncogene in breast cancer. Carcinogenesis. 2012;33(11):2007-2017.

83. Bidard FC, Matthieu MC, Chollet P, et al. p53 status and efficacy of primary anthracyclines/alkylating agent-based regimen according to breast cancer molecular classes. Ann Oncol. 2008;19(7):1261-1265.

84. Liedtke C, Mazouni C, Hess KR, et al. Response to neoadjuvant therapy and long-term survival in patients with triple-negative breast cancer. J Clin Oncol. 2008;26(8):1275-1281.

85. von Minckwitz G, Untch M, Nüesch E, et al. Impact of treatment characteristics on response of different breast cancer phenotypes: pooled analysis of the German neo-adjuvant chemotherapy trials. Breast Cancer Res Treat. 2011;125(1):145-156.

86. von Minckwitz G, Untch M, Blohmer JU, et al. Definition and impact of pathologic complete response on prognosis after neoadjuvant chemotherapy in various intrinsic breast cancer subtypes. J Clin Oncol. 2012;30(15):1796-1804.

87. Untch M, Jackisch C, Schneeweiss A, et al; German Breast Group (GBG); Arbeitsgemeinschaft Gynäkologische Onkologie-Breast (AGO-B) Investigators. Nab-paclitaxel versus solvent-based paclitaxel in neoadjuvant chemotherapy for early breast cancer (GeparSepto-GBG 69): a randomised, phase 3 trial. Lancet Oncol. 2016;17(3):345-356.

88. Gianni L, Mansutti M, Anton A, et al. ETNA (evaluating treatment with neoadjuvant abraxane) randomized phase III study comparing neoadjuvant nab-paclitaxel (nab-P) versus paclitaxel (P) both followed by anthracycline regimens in women with HER2-negative high-risk breast cancer: a MICHELANGO study. J Clin Oncol. 2016;34(Suppl 15):abstract 502.
89. Kuwayama T, Yamauchi H, Takano T, et al. Primary analysis of a randomized phase II, multicenter trial: neoadjuvant weekly nab-paclitaxel $100 \mathrm{mg} / \mathrm{m}^{2}$ followed by $\mathrm{FE}_{100} \mathrm{C}$ compared with docetaxel $75 \mathrm{mg} / \mathrm{m}^{2}$ followed by $\mathrm{FE}_{100} \mathrm{C}$ for early breast cancer in Japan. J Clin Oncol. 2015;33(Suppl 28):abstract 136.

90. Stefansson OA, Villanueva A, Vidal A, Martí L, Esteller M. BRCA1 epigenetic inactivation predicts sensitivity to platinumbased chemotherapy in breast and ovarian cancer. Epigenetics. 2012;7(11):1225-1229.

91. Chen XS, Yuan Y, Garfield DH, Wu JY, Huang O, Shen KW. Both carboplatin and bevacizumab improve pathological complete remission rate in neoadjuvant treatment of triple negative breast cancer: a meta-analysis. PLoS One. 2014;9(9):e108405.

92. Hurley J, Reis IM, Rodgers SE, et al. The use of neoadjuvant platinumbased chemotherapy in locally advanced breast cancer that is triple negative: retrospective analysis of 144 patients. Breast Cancer Res Treat. 2013;138(3):783-794.

93. von Minckwitz G, Martin M. Neoadjuvant treatments for triple-negative breast cancer (TNBC). Ann Oncol. 2012;23(Suppl 6):vi35-vi39.

94. Petrelli F, Coinu A, Borgonovo K, et al. The value of platinum agents as neoadjuvant chemotherapy in triple-negative breast cancers: a systematic review and meta-analysis. Breast Cancer Res Treat. 2014;144(2):223-232.

95. Sikov WM, Dizon DS, Strenger R, et al. Frequent pathologic complete responses in aggressive stages II to III breast cancers with every4-week carboplatin and weekly paclitaxel with or without trastuzumab: a Brown University Oncology Group Study. J Clin Oncol. 2009;27(28):4693-4700.

96. Chen XS, Nie XQ, Chen CM, et al. Weekly paclitaxel plus carboplatin is an effective nonanthracycline-containing regimen as neoadjuvant chemotherapy for breast cancer. Ann Oncol. 2010;21(5):961-967.

97. Roy V, Pockaj BA, Allred JB, et al. A Phase II trial of docetaxel and carboplatin administered every 2 weeks as preoperative therapy for stage II or III breast cancer: NCCTG study N0338. Am J Clin Oncol. 2013;36(6):540-544.

98. Chang HR, Glaspy J, Allison MA, et al. Differential response of triple-negative breast cancer to a docetaxel and carboplatin-based neoadjuvant treatment. Cancer. 2010;116(18):4227-4237.

99. Campos Gomez S, Campos Gomez KA, Garcia Garces M, Morelos G, Hernandez Alvarez J. Neoadjuvant carboplatin and docetaxel in locally advanced triple negative breast cancer: a Hispanic trial. J Clin Oncol. 2016;34(Suppl 15):abstract e12554.

100. von Minckwitz G, Schneeweiss A, Loibl S, et al. Neoadjuvant carboplatin in patients with triple-negative and HER2-positive early breast cancer (GeparSixto; GBG 66): a randomised phase 2 trial. Lancet Oncol. 2014;15(7):747-756.

101. Enriquez D, Poma Nieto N, Fuentes HA, Guerra H, Ruiz Mendoza RE, Gomez HL. Improving pathological response in locally advanced triple negative breast cancer: comparison between $\mathrm{CbD}$ and AC-T regimens. J Clin Oncol. 2017;35(Suppl 15):abstract 585.

102. Kaklamani VG, Jeruss JS, Hughes E, et al. Phase II neoadjuvant clinical trial of carboplatin and eribulin in women with triple negative early-stage breast cancer (NCT01372579). Breast Cancer Res Treat. 2015;151(3):629-638.

103. Northwestern University. Carboplatin and eribulin mesylate in triple negative breast cancer patients. Avalaible from: https://clinicaltrials.gov/ct2/show/NCT01372579. NLM identifier: NCT01372579. Accessed June 1, 2011.

104. Petrelli F, Cabiddu M, Coinu A, et al. Adjuvant dose-dense chemotherapy in breast cancer: a systematic review and meta-analysis of randomized trials. Breast Cancer Res Treat. 2015;151(2):251-259.

105. Reinisch M, Ataseven B, Kümmel S. Neoadjuvant dose-dense and dose-intensified chemotherapy in breast cancer - review of the literature. Breast Care (Basel). 2016;11(1):13-20.

106. Hastak K, Alli E, Ford JM. Synergistic chemosensitivity of triplenegative breast cancer cell lines to poly(ADP-Ribose) polymerase inhibition, gemcitabine and cisplatin. Cancer Res. 2010;70(20): 7970-7980. 
107. Alli E, Sharma VB, Sunderesakumar P, Ford JM. Defective repair of oxidative dna damage in triple-negative breast cancer confers sensitivity to inhibition of Poly(ADP-ribose) polymerase. Cancer Res. 2009;69(8):3589-3596.

108. Gelmon KA, Tischkowitz M, Mackay H, et al. Olaparib in patients with recurrent high-grade serous or poorly differentiated ovarian carcinoma or triple-negative breast cancer: a phase 2, multicentre, open-label, non-randomised study. Lancet Oncol. 2011;12(9):852-861.

109. Balmaña J, Tung NM, Isakoff SJ, et al. Phase I trial of olaparib in combination with cisplatin for the treatment of patients with advanced breast, ovarian and other solid tumors. Ann Oncol. 2014;25(8):1656-1663.

110. Somlo G, Frankel PH, Luu TH, et al. Efficacy of the combination of ABT-888 (veliparib) and carboplatin in patients with BRCA-associated breast cancer. J Clin Oncol. 2013;31(Suppl 15):abstract 1024.

111. Pahuja S, Beumer JH, Appleman LJ, et al. A phase I study of veliparib (ABT-888) in combination with weekly carboplatin and paclitaxel in advanced solid malignancies and enriched for triple-negative breast cancer (TNBC). J Clin Oncol. 2015;33(Suppl 15):abstract 1015.

112. Kummar S, Chen A, Ji J, et al. Phase I study of PARP inhibitor ABT- 888 in combination with topotecan in adults with refractory solid tumors and lymphomas. Cancer Res. 2011;71(17):5626-5634.

113. Telli ML, Jensen KC, Vinayak S, et al. Phase II study of gemcitabine, carboplatin, and iniparib as neoadjuvant therapy for triple-negative and BRCA1/2 mutation-associated breast cancer with assessment of a tumor-based measure of genomic instability: PrECOG 0105. J Clin Oncol. 2015;33(17):1895-1901.

114. Rugo HS, Olapade O, DeMichele A, et al. Veliparib/carboplatin plus standard neoadjuvant therapy for high-risk breast cancer: first efficacy results from the I-SPY 2 TRIAL. Cancer Res. 2013;73(24 Suppl):Abstract nr S5-02.

115. Geyer CE, O'Shaughnessy J, Untch M, et al. Phase 3 study evaluating efficacy and safety of veliparib (V) plus carboplatin $(\mathrm{Cb})$ or $\mathrm{Cb}$ in combination with standard neoadjuvant chemotherapy (NAC) in patients (pts) with early stage triple-negative breast cancer (TNBC). J Clin Oncol. 2017;35(Suppl 15):abstract 520.

116. M.D. Anderson Cancer Center. Neoadjuvant talazoparib for patients with a BRCA deleterious mutation. Available from: https://clinicaltrials.gov/ct2/show/NCT02282345. NLM Identifier: NCT02282345. Accessed October 30, 2014.

117. Greenberg S, Rugo HS. Triple-negative breast cancer: role of antiangiogenic agents. Cancer J. 2010;16(1):33-38.

118. von Minckwitz G, Eidtmann H, Rezai M, et al; German Breast Group; Arbeitsgemeinschaft Gynäkologische Onkologie-Breast Study Groups. Neoadjuvant chemotherapy and bevacizumab for HER2negative breast cancer. $N$ Engl J Med. 2012;366(4):299-309.

119. Thomssen C, Pierga JY, Pritchard KI, et al. First-line bevacizumabcontaining therapy for triple-negative breast cancer: analysis of 585 patients treated in the ATHENA study. Oncology. 2012;82(4): 218-227.

120. O’Shaughnessy J, Romieu G, Diéras V, Byrtek M, Duenne A-A, Miles D. Meta-analysis of patients with triple-negative breast cancer (TNBC) from three randomized trials of first-line bevacizumab (BV) and chemotherapy treatment for metastatic breast cancer (MBC). Cancer Res. 2010;70(24 Suppl):P6-12-03.

121. Earl HM, Hiller L, Dunn JA, et al; ARTemis Investigators. Efficacy of neoadjuvant bevacizumab added to docetaxel followed by fluorouracil, epirubicin, and cyclophosphamide, for women with HER2-negative early breast cancer (ARTemis): an open-label, randomised, phase 3 trial. Lancet Oncol. 2015;16(6):656-666.

122. Sikov WM, Berry DA, Perou CM, et al. Impact of the addition of carboplatin and/or bevacizumab to neoadjuvant once-per-week paclitaxel followed by dose-dense doxorubicin and cyclophosphamide on pathologic complete response rates in stage II to III triple-negative breast cancer: CALGB 40603 (Alliance). J Clin Oncol. 2015;33(1): 13-21.
123. Golshan M, Cirrincione CT, Carey LA, et al. Impact of neoadjuvant therapy on breast conservation rates in triple-negative and HER2positive breast cancer: combined results of CALGB 40603 and 40601 (Alliance). J Clin Oncol. 2015;33(Suppl 15):abstract 1007.

124. Guarneri V, Dieci MV, Bisagni G, et al. Preoperative carboplatinpaclitaxel-bevacizumab in triple-negative breast cancer: final results of the phase II Ca.Pa.Be study. Ann Surg Oncol. 2015;22(9):2881-2887.

125. Kim HR, Jung KH, Im SA, et al. Multicentre phase II trial of bevacizumab combined with docetaxel-carboplatin for the neoadjuvant treatment of triple-negative breast cancer (KCSG BR-0905). Ann Oncol. 2013;24(6):1485-1490.

126. Nahleh ZA, Barlow WE, Hayes DF, et al. SWOG S0800 (NCI CDR0000636131): addition of bevacizumab to neoadjuvant nabpaclitaxel with dose-dense doxorubicin and cyclophosphamide improves pathologic complete response (pCR) rates in inflammatory or locally advanced breast cancer. Breast Cancer Res Treat. 2016;158(3):485-495.

127. Mrózek E, Layman R, Ramaswamy B, et al. Phase II trial of neoadjuvant weekly nanoparticle albumin-bound paclitaxel, carboplatin, and biweekly bevacizumab therapy in women with clinical stage II or III HER2-negative breast cancer. Clin Breast Cancer. 2014;14(4):228-234.

128. Schmid P, Park YH, Muñoz-Couselo E, et al. Pembrolizumab (pembro) + chemotherapy (chemo) as neoadjuvant treatment for triple negative breast cancer (TNBC): preliminary results from KEYNOTE-173. $J$ Clin Oncol. 2017;35(Suppl 15):abstract 556.

129. Nanda R, Liu MC, Yau C, et al. Pembrolizumab plus standard neoadjuvant therapy for high-risk breast cancer (BC): results from I-SPY 2. J Clin Oncol. 2017;35(Suppl 15):abstract 506.

130. Fondazione Michelangelo. Neoadjuvant therapy in TRIPle negative breast cancer with antiPDL1 (NeoTRIPaPDL1). Available from: https://clinicaltrials.gov/ct2/show/NCT02620280. NLM Identifier: NCT02620280. Accessed November 3, 2015.

131. M.D. Anderson Cancer Center. Triple-negative first-line study: neoadjuvant trial of nab-paclitaxel and MPDL3280A, a Pdl-1 inhibitor in patients with triple negative breast cancer. Avalaible from: https://clinicaltrials.gov/ct2/show/NCT02530489. NLM Identifier: NCT02530489. Accessed August 19, 2015.

132. Yale University. Neoadjuvant MEDI4736 concomitant with weekly nabpaclitaxel and dose-dense AC for stage I-III triple negative breast cancer. Available from: https://clinicaltrials.gov/ct2/show/NCT02489448. NLM Identifier: NCT02489448. Accessed July 1, 2015.

133. Merck Sharp \& Dohme Corp. Safety and efficacy study of pembrolizumab (MK-3475) in combination with chemotherapy as neoadjuvant treatment for participants with triple negative breast cancer (TNBC) (MK-3475-173/KEYNOTE 173). Available from: https://clinicaltrials. gov/show/NCT02622074. NLM Identifier: NCT02622074. Accessed December 2, 2015.

134. National Cancer Institute (NCI). Pembrolizumab in treating patients with triple-negative breast cancer. Available from: https://clinicaltrials.gov/ct2/show/NCT02954874. NLM Identifier: NCT02954874. Accessed November 3, 2016.

135. Pierfranco Conte, Istituto Oncologico Veneto IRCCS. Adjuvant treatment for high-risk triple negative breast cancer patients with the anti-PD-11 antibody avelumab (A-Brave). Available from: https://clinicaltrials.gov/ct2/show/NCT02926196. NLM Identifier: NCT02926196. Accessed October 5, 2016.

136. Senkus E, Kyriakides S, Ohno S, et al; ESMO Guidelines Committee. Primary breast cancer: ESMO Clinical Practice Guidelines for diagnosis, treatment and follow-up. Ann Oncol. 2015;26(Suppl 5):v8-v30.

137. Denduluri N, Somerfield MR, Eisen A, et al. Selection of optimal adjuvant chemotherapy regimens for human epidermal growth factor receptor 2 (HER2) - negative and adjuvant targeted therapy for HER2positive breast cancers: an American Society of Clinical Oncology Guideline Adaptation of the Cancer Care Ontario Clinical Practice Guideline. J Clin Oncol. 2016;34(20):2416-2427. 
Cancer Management and Research

\section{Publish your work in this journal}

Cancer Management and Research is an international, peer-reviewed open access journal focusing on cancer research and the optimal use of preventative and integrated treatment interventions to achieve improved outcomes, enhanced survival and quality of life for the cancer patient

The manuscript management system is completely online and includes

Submit your manuscript here: https://www.dovepress.com/cancer-management-and-research-journal 